\title{
A first approach to the possible urban form of the city of Alcoy for the 21 st century
}

\author{
Ivo Vidal Climent, Ciro Vidal Climent, Vicente Vidal Vidal \\ Escuela Técnica Superior de Arquitectura, Universitat Politécnica de València. Valencia, Spain \\ E-mail: ivvicli@pra.upv.es, civicli@pra.upv.es, estudiovvv@estudiovvv.com
}

\begin{abstract}
The will of Modernity to define and decide the urban form has been truncated by an endless succession of conditions related to land ownership and the many ways of justifying compliance with all kinds of rules that elude the question about form. The consequence is that they provoke a distortion of reality by blurring the entity of the city and its position in front of history.In this sense, the drift and banalization of urbanism has been directed by the bureaucratic criteria of an administration that, with or without technical knowledge, makes decisions that impact on the urban form but without acquiring commitment or responsibility towards it. The urban form is at the mercy of the local building legislation, of the road or the shape of the plots susceptible or not to be built. Irremediably, the resulting urban form, achieved both in an active and passive way, evidences the error of the procedure because it reveals an operational ignorance of the context, of history, or simply of the faith in progress. From the shelter of thought that represents the discipline of urbanism we introduce a series of urban solutions for the city of Alcoy that correspond to a possible urban proposal bounded in the time of the XXI century. This study aims to have a view of the urban form and urbanist order for the city of Alcoy and its territory under the premises of understanding both the inherited city and the needs of the new generations committed to a possible future.
\end{abstract}

Keywords: industrial city, urban project, sense of citizenship, urban things, territorial laws.

\section{The city in the territory}

The city of Alcoy stands on the valley of l'Alcoia, the valley is governed by the law that emanates from its rivers and adjacent lands. The Molinar river, with a steep hydraulic elevation (3\%) and the Riquer or Barxell river, with a more gentle slope $(1.5 \%)$, join to form the old Alcoy river, now called the Serpis river.

The valley of 1'Alcoià results from the intersection of the rambles and banks of the three rivers. With an average section of 50x 400 $\mathrm{m}$ the east-west breeze is responsible for keeping the valley clean of pollution.

\section{Topography}

Dealing with this inherited topography, the city is stabilized through the definition of a service plan that includes the old village and urban sprawl between levels 525 and 540 .

This plane is so dominant that the morphological unity of City would not be comprehensible without it. Establishing the city's reference plane is as much as affirming its scale, its routes and its urban perception as a continuum.

The service plane obviates the planimetric discontinuities between the channels and the layout of the streets as the bridges provide the necessary connection to sew the banks and distract us from that discontinuity. The coherence of the bridges joining the streets produces in its inhabitants the perception or the feeling that the city is a continuous whole. 


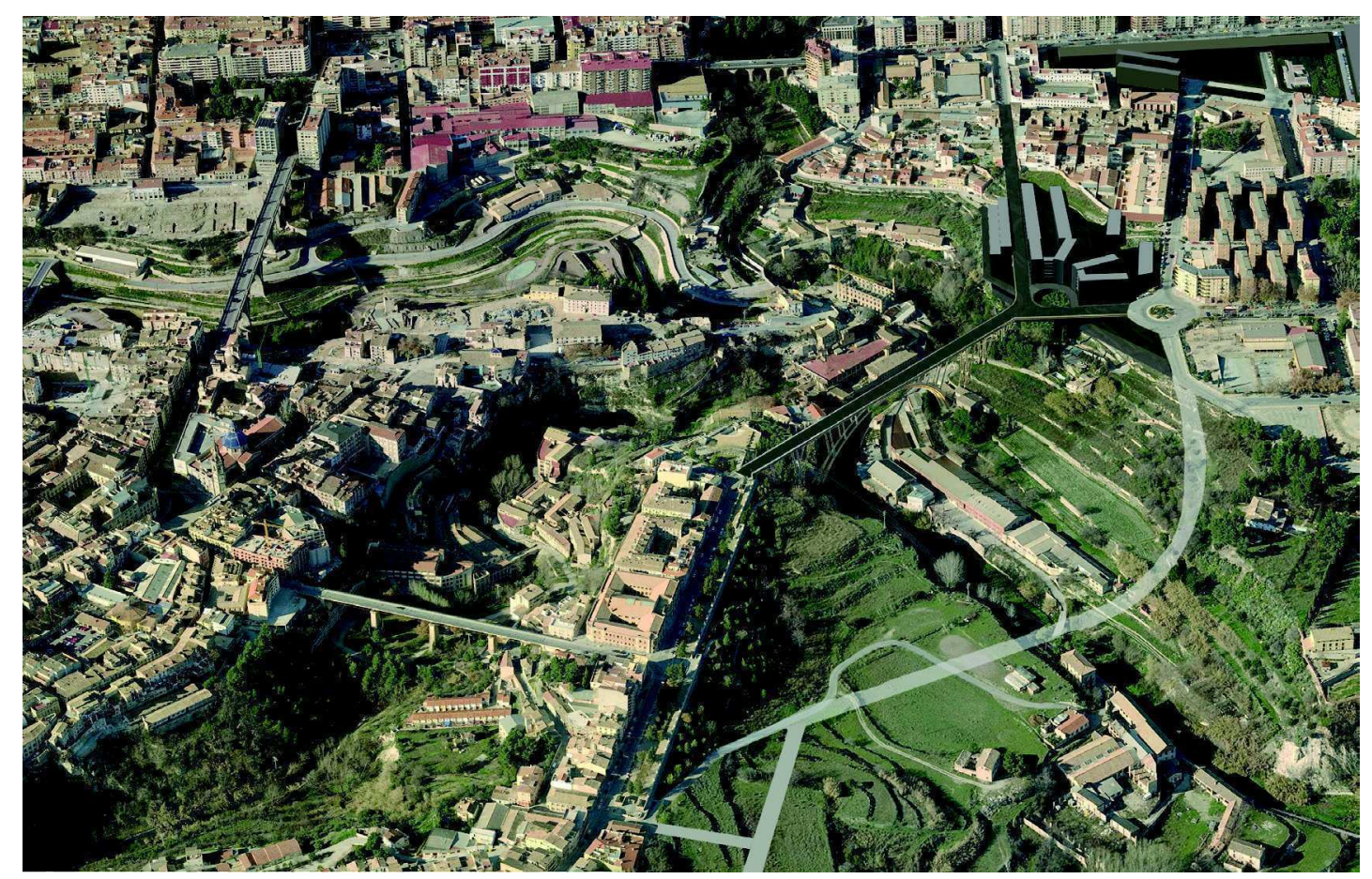

Figure 1.

View of the new Y shaped Viaduct bridge that connects Viaduct and Northern zone. OVVV

Axis and service planes

In 1847 Joan Subercase, with an enlightened vision, traced the straight axis of the Alameda from San Roque church to the Merita pool as a decidedly modern proposal, becoming 30 years later in the regulatory axis for the expansion project of Alcoy that gave rise to the idea of the service plan of the city.

Consequently, when making the road from Játiva to Alicante in 1861, the bridges of San Roque and la Pechina were built in order to maintain that service plan of the city. As these works were funded by the State and the decision of straight alignment involved expensive bridges that were avoidable by going around the ravines, the City Council assumed the cost difference in anticipation of a safe repayment for the future of the city. This decision was physically translated into the main axis of the city with a length of almost two kilometers and was the basis on which the geometry of the 1878 extension of the city was drawn. In a city with so great topographical differences the only way to catch sight of the new century was through the collective consciousness of that regulatory plane interpreted under the sign of the air.

\section{Poposal for the XXIst century}

\section{Bridges}

For a city heiress of this know-how, the union of the Viaduct neighborhood with the North neighborhood is proposed through a bridge that links the lower end of the Viaduct walk and the middle height of the Northern zone through a double connection: the extension of Andalusia avenue and l'Escorxador street.

Andalusia avenue is an axis that vertebrates the north zone along with the Hispanitat avenue. The node where both avenues converge is of enormous importance for the future of the city because it offers a straight opening in direction and height to the highway. L'Escorxador street connects directly with Gil Albert avenue and is configured as the natural extension of the local walk along the bridges.

Tours

The walk along the bridges offers a daily perception of the city, less distracted than the mere anecdote and as structured as a habit. The bridges belong visually and organically to the street system and so any new bridge 


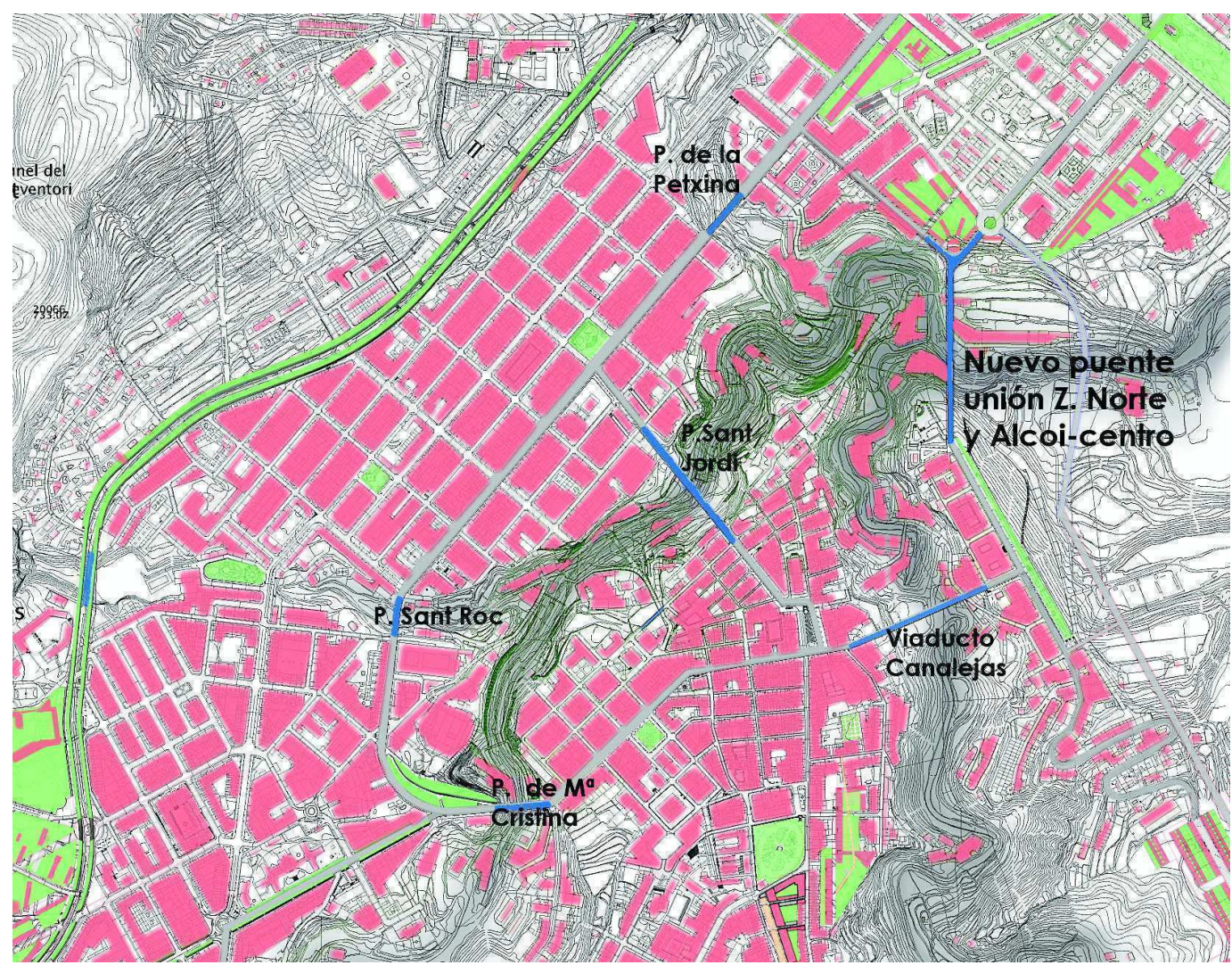

Figure 2.

Plan of the city showing the relation between the bridges and the two possible tours along them that pivot on St. George's bridge. $\odot$ VVV

must accept the street character of the bridges in Alcoy. Understanding the development of the city as a continuous fact the traditional walk along the bridges is extended with a second circuit that would be formed by the St. George's bridge, Canalejas' Viaduct, the new Y shaped Viaduct bridge and Pechina bridge. This second ring offers a new territorial image that unifies city and valley. Finding the meaning of the city is a task to be taken up again. We must maintain the relation of this complex modern creation, the industrial city, with the physiocratic heritage that still shows itself in the surrounding territory as a whole. The current city still clearly shows through its industrial character the importance it had when in the nineteenth century it was maintained and adressed by a solid industrial culture.

Industry.

The industrial activity of the city was started when the general systems for production focused on the generation and channeling of energy, access and the availability of useful land near the places of residence. In this way the industries of the Molinar ensemble could take advantage of the hands given by the force of the water. The order of the hydraulic wheels and the factories were subordinated to the territorial order under the sign of the water and they found a peaceful form of rest between the works of the man and the nature. In Alcoy the primary order of the distribution of water was established as a foundational principle of its identity.

Due to the dispersion of the industry in the city there must be an indexation of the industries that develop activity not only in the industrial sectors but also in the historic center so that the transfer of those that lose competitiveness because of its location and accessibility can be grouped through a more evolved territorial organizational model than the mere delimitation of a sector.

This higher order organizational stage consists of a ring that interweaves all industrial areas currently scattered and disconnected 


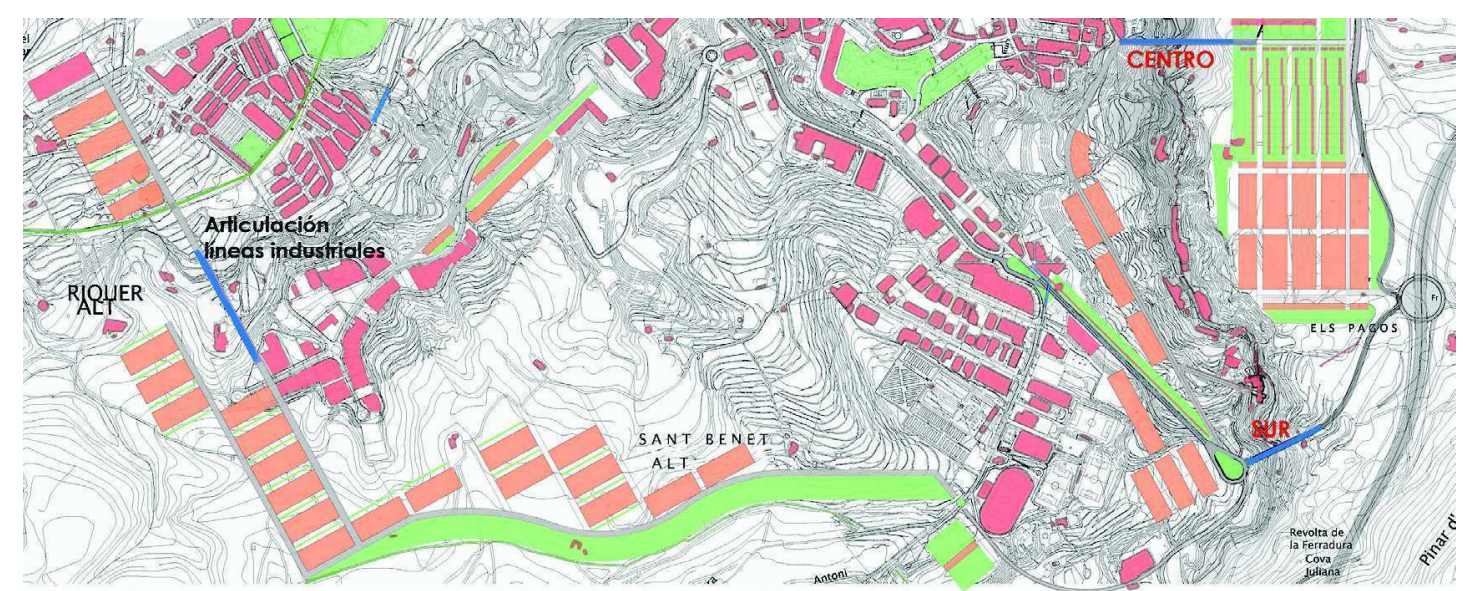

Figure 3.

Articulation of the industrial lines in Riquer Alt, Sant Benet alt, Molinar and Pagos. CVVV

amongst them. This articulation of the different industrial sectors consists of an industrial line with an extension of half a million square meters of industrial land that connects the West an South entrances of the city. The line begins in Batoi, in front of the existing Serpis factory, goes through Riquer Alt offering a new way out to Sant Benet sector, then slopes into the mountain until it reaches the dismanteled railroad of the now called Green path and follows it until the Sports zone. With a new detour it gets to the southern entrance of the city and from there it can either slope down with a $5 \%$ ramp into the Molinar area or connect with the generous Pagos area and, exiting to the highway, with the Northern side of the city.

\section{Territorial laws}

"Man produces rules, nature is governed by laws. Without the knowledge of the law, without the feeling of the law, nothing can be done. Nature produces both. The mind desires things and defies nature to produce that which expresses the inexpressible, the indefinable, the inconmensurate, that which has no substance, love, hate or nobility. The mind wants to express everything but it can't do that without an instrument. The law is the builder of the instruments. We should all consider rules modifiable and laws immutable." Kahn, 1961:4 Territorial laws are permanent and show the relationships between topography, roads, rivers, waterfalls, sources and channels as elements that make up a place beyond its immediate usefulness. Other less obvious laws are within a complex order that, concealed in history or latent in the atmosphere of the place, can give rise to a formulation of the principles governing the disposition of industry and urban units. In the project of the city it is necessary to establish rules that allow to incorporate the sense of the laws to the urban order. Everything is broad and distant in the law, but through the rules, when enforcing them in the field of the construction of the city, everything gets accurate.

Accepting the laws that give rise to the shape of settlements in the territory, the rules that decide the territorial morphology are subordinated to the principles emanated from history, geology and topography.

City and territory are inseparable. Therefore, when the new route of the north highway is incorporated into the territory, it should be used in favor of the altogether image, maintaining and extending the service plane, visually gaining the valley and approaching the distant traffic of the highway. It is also necessary that the city takes advantage of the road access to gain an additional territorial level. In the urban scale the city-highway connection must provide a clarity that revitalizes the urban structure, improving the streets, avenues and gardens that belong to the everyday use.

The display of a territorial network as the variant of the highway to Alicante has to be able to be assumed by the industrial city as a positive value articulating a new axis of access to the Northern zone and revitalizing both the access to the Cotes Baixes industry and 


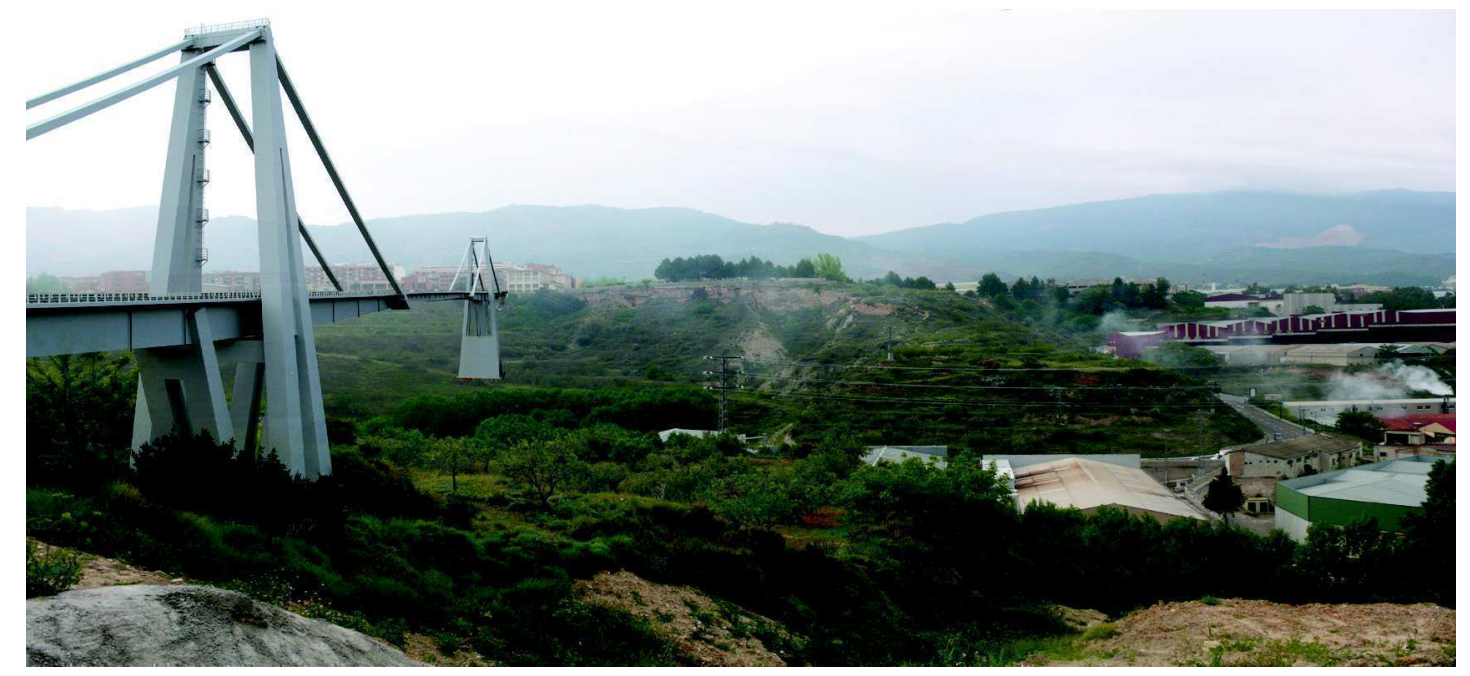

Figure 4

View of unbuilt Northern bridge defining a horizontal service plane of the city. $\mathrm{CVVV}$

the arrival at the hospital. The creation of the new bridge as the northern access respects the valley and affirms the level of the service plan of the city giving continuity to that particular atmosphere that the bridges generate.

In that step of territorial adaptation we find an old user of the valley in the railroad. And it would reinforce the regional vocation if the health infrastructure of the hospital could be served by such an efficient transport. The modernization of the railway in the city should evaluate the transference of the tracks to the level of the middle plane of the city for its modal interconnection with the bus station and its real approach to the citizen.

Institutions.

The general hospital is configured as a health institution that marks the role of a city of regional relevance because no other institution has the power to bring in together such services and specialized jobs. Its optimization and updating necessarily influences the quality of life of the inhabitants and their expectations as social beings within a welfare project. The existence of a hospital is not understood without the collaboration of research institutes attached to the center and in connection with other institutes throughout the country. To have the possibility of increasing the services of this institution implies the solution of a clear accessibility and a foresight of space in continuity with the existing infrastructure.
Given the specific weight and the relation of immediacy between the transport center and the sanitary complex, the institutional vocation of Al-Azraq square needs a unitary project that integrates gardens, edification and free spaces. The set of courts, treasury, general archives and municipal library can find their precise setup in this location, coexisting with a hybrid program of homes, offices, shops and kindergarten.

The University as a social operator of knowledge also needs historical memory. For this reason the rescue and reuse of abandoned structures gives notice of a continuous progress of the society. The models of restoration of the Molinar ensemble, beyond the direct reference to the museum, have the capacity to generate shared spaces that serve for the study and the transfer of knowledge as well as to facilitate a type of multidisciplinary contact that is the basis of the creative knowledge.

The modern research and development units not only need large laboratory units but also a transversal theoretical support that is the engine of the advances and the progression in the search of the knowledge. Support spaces are needed in the daily working environment of researchers, which facilitate alternative and autonomous discussion routes that do not involve a much more complex and expensive research process. For this purpose it is extremely useful that the landscaped environment of the buildings that host the lines of research and development can be an invitation to the walk and the conversation between experts. 


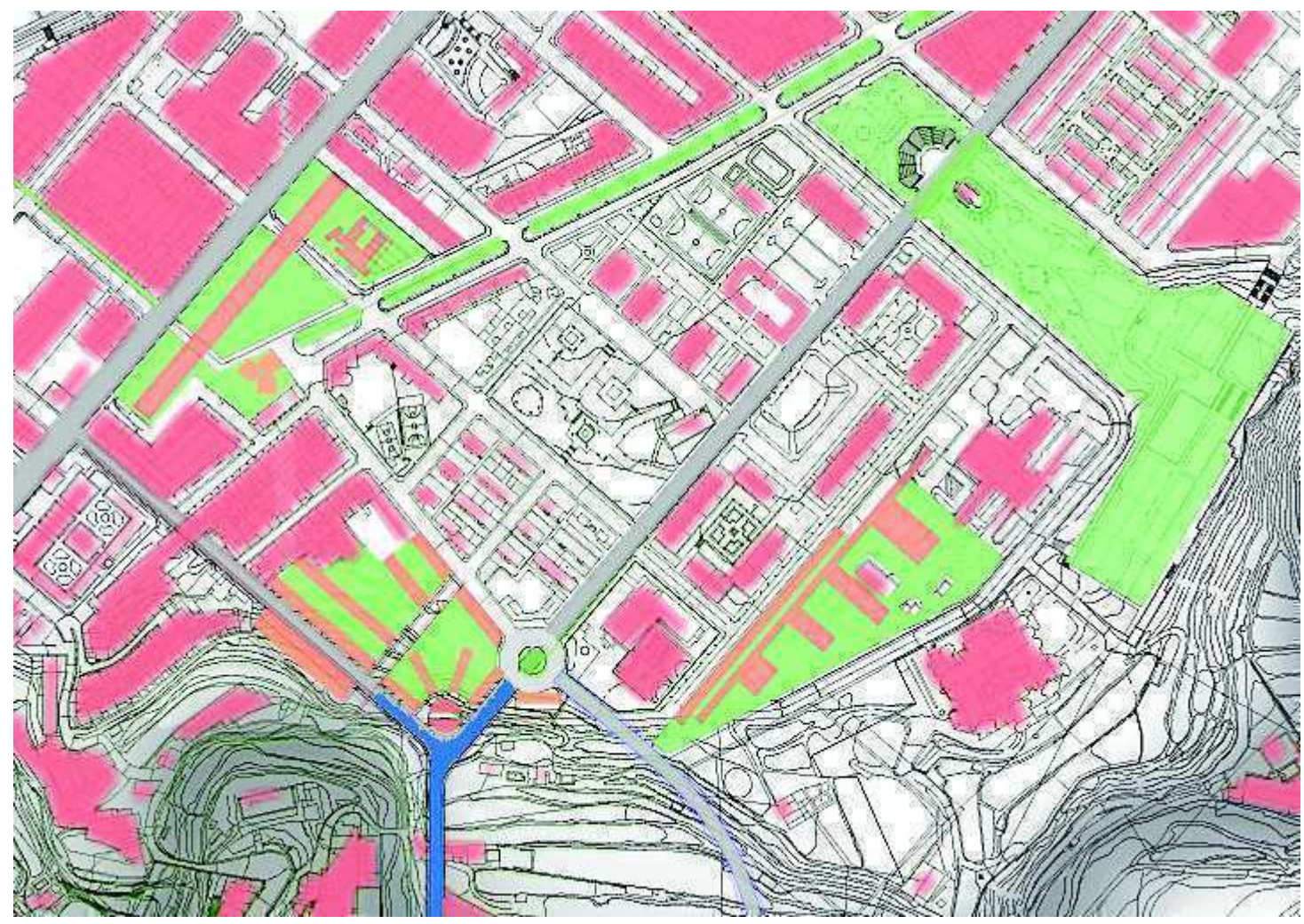

Figure 5.

Plan of the Northern zone with Al-Azraq square, the Hospital an the new Y shaped Viaduct bridge. COVVV

Housing

"The irresistible need for order is the highest mission of the civilized man... But in the aggregations of houses the sense of order is still seriously compromised by many barriers that oppose to a complete and perfect geometric realization". Pagano, 1938

The city of Alcoy, as an industrial city, has grown by accepting the menestral house and transforming it into working-class housing to accommodate the growing labor demanded by the industry. The urban form depends on the geometry to grow adding layers of coherence to the city, so this is the modern condition necessary to tame the overwhelming force of expansion of the city.

The city of this century must accept its territorial heritage, preserve paths and give a renovated coherence to the road structure, propose a rational plan of architectural rehabilitation of the historic center, improve its welfare values by updating existing dwelling buildings and accept the commercial vitality of the streets as an urban event of strong dynamism.
New growing sectors must develop alternative types of housing that are sensitive to the concept of essentiality inherent to the human being in full opposition to the stale program of real estate markets that reduce to the absurd the sense of a house with surface numbers, number of rooms, compliance with regulations and other common places that exclude excellent project openings for fear of what is not codified. The incorporation of the concept of life into the open and a social demand for more space at a price not increased by speculation should be extended to social housing of new construction.

\section{Conclusion}

A current analysis of the latest interventions in the city reveals how far they are from that rational certainty of a century and a half ago in the progress of civilization. Instead, the dictates that decide the shape of the city do not come from an intellectual base or an attentive look to 


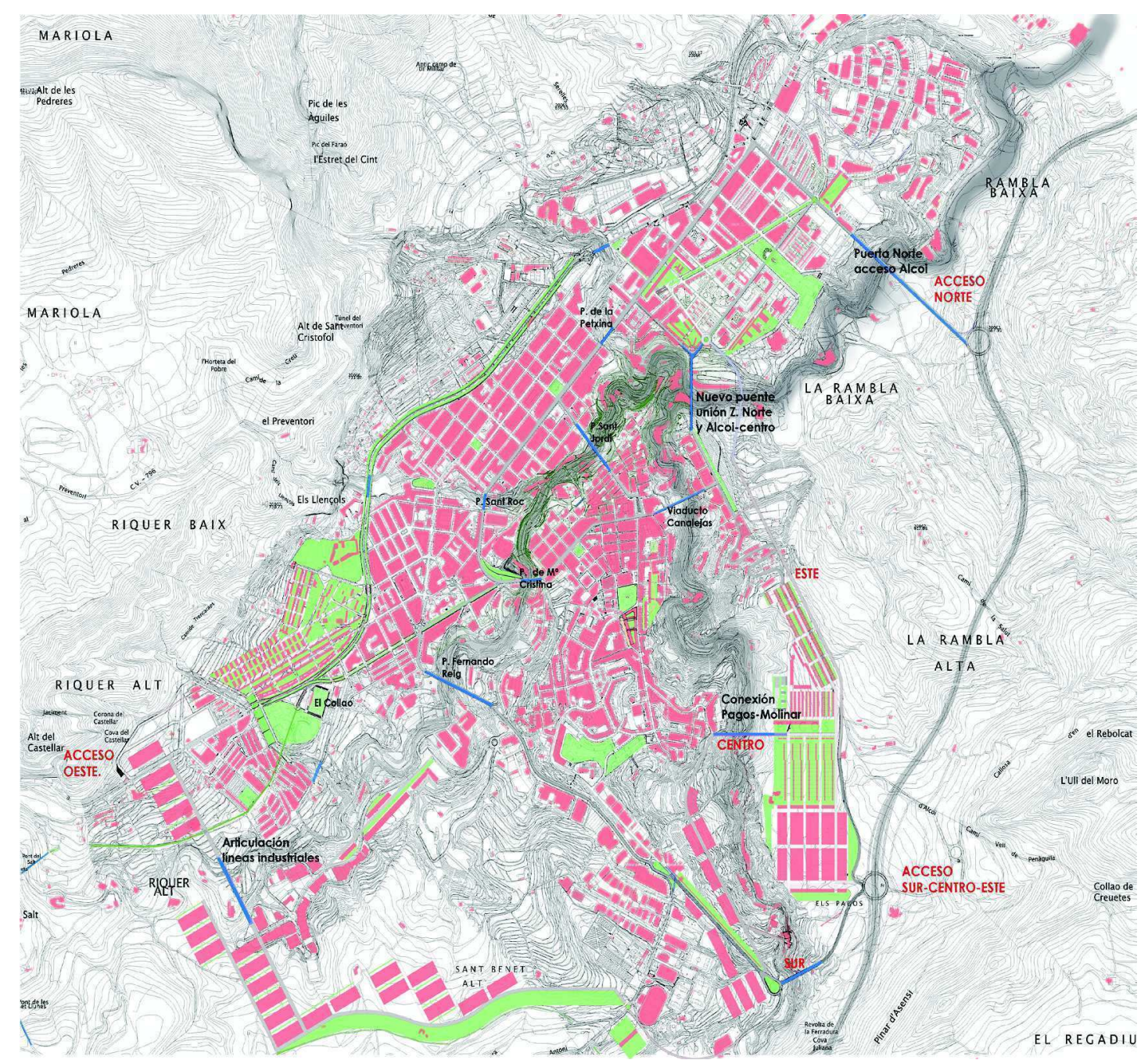

Figure 6.

Plan of Alcoy with the proposed extensions of the city. OVVV

the future. There is only an urbanistic prejudice linked to the registration of property and a fanatical conviction in the opportunity offered by the short term with a disturbing disregard for the dire consequences of decisions that are merely banal.

It is necessary to make a reading of the city trying to collect that theory felt by the conscience of the citizens and that made possible the growth and transformation of the industrial city. For Rousseau the individual could only acquire the sense of citizenship if he first rebelled against himself, acting as his own antagonist in order to adopt the general interest of the community. Lighted by this moral principle we can interpret the formal principle of the city. The primal forces that shaped it are the key to evaluate the guidelines that will make the city a coherent organism not depleted by isolated interventions that mortgage its future.

Knowledge about a discipline as complex as the city's urbanism is nourished by observation and attentive conversations around the multiple layers of reality. This must be interpreted from very calibrated points of view in order to be able to see what, obviously, goes unnoticed. The concepts that Solà-Morales bequeathed to us are linked to the way of understanding that the materiality of the city is necessary to verify the meaning of things and also to be able to follow the meaning of history. The urban form perceived by the citizen starts from the reality of the urban object. Thus corners, sidewalks, streets, squares, institutions, etc. are inserted in the idea of urban things where architecture seeks to accommodate idea and reality. 
The search for a coherent line in the city planning is a multi-scale problem. It assumes a principle of subordination where the traces belong to a logic of different scales that are present in the insertion of the gardens, the industries, the presence of its Archeology, or a corner, or the macroform as a territorial overlap. To a great city, a great form, in this way we can interpret New York or Cerdà's hypodamic urbanism. The urbanism of Alcoy is not only an act of interpreting its bridges, streets and alleys. There are traces in their territory to think of a favorable future, traces that are already induced and that need a careful observation to distinguish and propose them as rules that help us to show the interrelations between the paths, roads, bridges and neighborhoods. Everything is written in the territory and it is the task of urbanism to decipher its signs... Therefore, beyond a detailed description of its components, it is preferable to show through the iconic language of images the scope of an inductive system of propositions channeled through drawing, propositions that serve as a guide to think of that favorable future for the anonymous settlers of the territory of l'Alcoià.

\section{References}

Juliá, Ángel. Guía del Forastero en Alcoy, 1864. Jose Martí Casanova Librero Editor. Facsimil copy of the Biblioteca Valenciana collection. Librerías París-Valencia. Dep. Legal: V.2811-1990. Page 74.

Kahn, Louis I. Conference Law and Rule in Architecture. Princeton University November 29th 1961. Edited in italian in Casabella $\mathrm{n}^{\mathrm{o}}$ 693. October 2001. Translated by the author. Page 4 .

Pagano, Giuseppe. Fragmentos de CasabellaCostruzioni $\mathrm{n}^{\circ} 132$, dicembre 1938 reprinted in Architettura e città durante il fascismo. A cura di Cesare De Seta. Biblioteca di Cultura Moderna Laterza. 1976 Bari. Pages. 371373 